\title{
Les rapports entre le Parti communiste roumain et le Parti communiste de Grèce de 1956 à 1968 : de la déstalinisation à la scission du Parti grec (1968)
}

Relations between the Romanian Communist Party and the Greek Communist

Party from 1956 to 1968: from De-Stalinization to the Greek Party Split (1968)

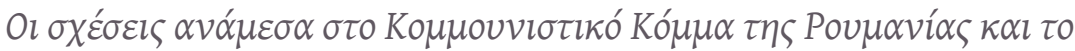

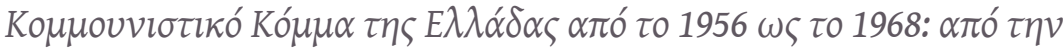

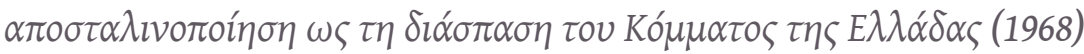

\section{Nikos Papadatos}

\section{(2) OpenEdition}

\section{Édition électronique}

URL : https://journals.openedition.org/ceb/9686

DOI : $10.4000 /$ ceb.9686

ISSN : 2261-4184

Éditeur

INALCO

\section{Édition imprimée}

ISBN : 978-2-85831-239-9

ISSN : 0290-7402

\section{Référence électronique}

Nikos Papadatos, «Les rapports entre le Parti communiste roumain et le Parti communiste de Grèce de 1956 à 1968 : de la déstalinisation à la scission du Parti grec (1968) », Cahiers balkaniques [En ligne] 44 | 2016, mis en ligne le 05 décembre 2017, consulté le 07 juillet 2021. URL : http:// journals.openedition.org/ceb/9686; DOI : https://doi.org/10.4000/ceb.9686

Ce document a été généré automatiquement le 7 juillet 2021.

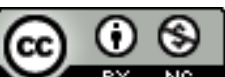

Cahiers balkaniques est mis à disposition selon les termes de la Licence Creative Commons Attribution - Pas d'Utilisation Commerciale 4.0 International. 


\section{Les rapports entre le Parti} communiste roumain et le Parti communiste de Grèce de 1956 à 1968 : de la déstalinisation à la scission du Parti grec (1968)

Relations between the Romanian Communist Party and the Greek Communist Party from 1956 to 1968: from De-Stalinization to the Greek Party Split (1968)

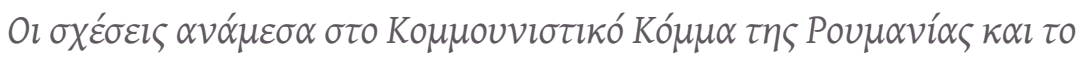

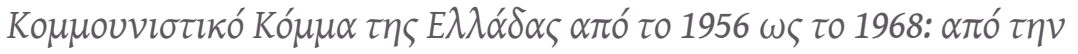

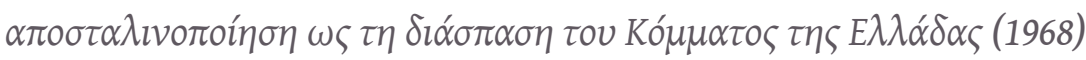

\section{Nikos Papadatos}

\section{Préambule : le Parti communiste de Grèce de 1918 à 1956}

Le Parti socialiste ouvrier grec, créé en novembre 1918, fut transformé, en novembre 1924, en Parti communiste de Grèce (KKE). De 1931 à 1956, à la suite de l'intervention de l'Internationale communiste (Komintern), le Parti grec participa à des luttes cruciales pour le pays : il devint l'organisateur principal de la Résistance grecque en fondant, en 1941, l'EAM (Front national de libération) et, en 1942, l'ELAS (Armée populaire de libération nationale). Après l'armistice et les accords de Varkiza (janvier-février 1945), les communistes grecs s'opposèrent aux forces gouvernementales dans la guerre civile (1946-1949). En 1949, après la défaite de l'Armée démocratique (l'AD fut l'armée des partisans grecs) dans cette guerre, le Parti et ses militants durent s'exiler en URSS et dans les démocraties populaires. De 1956 à 1968, à la suite des ingérences multiformes de l'Union soviétique dans la vie intérieure 
du KKE, les communistes grecs firent face à plusieurs crises internes jusqu'à ce qu'en 1968, le Parti communiste de Grèce se scinde en deux partis dits assez vite, "parti de l'intérieur » et " parti de l'extérieur »; les disputes et les différends dans la direction du Parti grec éclatèrent dans la Roumanie de Ceauşescu, siège du CC (Comité central) du KKE jusqu'en 1968, en déstabilisant complètement les anciens camarades dans une conjoncture historique marquée par la crise de la dictature en Grèce (avril 1967 juillet 1974).

2 Dès l'arrivée de Nikos Zachariadis au poste de secrétaire général du KKE en 1931, des efforts furent entrepris pour inculquer des règles soviétiques dans la politique du Parti, efforts qui se poursuivirent jusque dans les années 1950. La tendance à l'universalisation de ces principes relevait d'un engagement idéologique. Dans les années 1950, la bolchevisation du KKE ne se limitait pas simplement à l'approbation de la suprématie du Parti communiste de l'Union soviétique (PCUS). Ce n'était pas seulement le léninisme ou les principes bolcheviks qui devaient mobiliser la conscience des communistes grecs. L'universalisme bolchevik prôné par le KKE exaltait « les liens indissolubles entre le peuple de la Grèce et le grand peuple russe » et encore «la profonde gratitude exprimée par le peuple grec envers le grand peuple russe ». Le KKE reconnaissait l'URSS comme « le phare » qui amènerait, plus ou moins vite, l'humanité au socialisme, puis au communisme.

3 À partir de 1956, la politique soviétique fut directement liée à l'arrivée de Nikita Khrouchtchev au pouvoir. Citons François Fejtö :

Les différences culturelles entre les $\mathrm{PC}$ des démocraties populaires éclatèrent au grand jour pendant la période de déstalinisation, à la suite de la tentative de Khrouchtchev de réformer les méthodes d'action et les relations entre les « Partis frères ». En reconnaissant, dans sa déclaration de Belgrade de mai 1955 et celle de Moscou du 31 octobre 1956, la «pluralité des voies vers le socialisme », le numéro un soviétique ouvrait la porte à deux manifestations opposées des tendances autonomistes refoulées $[. . .]^{1}$.

4 En 1956, les formes que prit la "dézachariadisation ", autrement dit le limogeage de Zachariadis par la direction soviétique, ouvrirent la voie à une bataille fratricide dans les rangs des communistes grecs. Cela dans la mesure où elles visaient à annihiler tant la combativité que l'intégrité morale et politique de l'ancien secrétaire général. Zachariadis était constamment appelé par ses camarades le "petit Staline ", celui qui aurait conduit les communistes grecs à la victoire. Cette politique soviétique touchait donc au symbolique, à ce qui constituait, et, croyons-nous, constitue encore, le tréfonds de la résistance psychique et, en dernier ressort, politique. Et ceci, parce que la fin ignominieuse d'un symbole signifie bien plus qu'une défaite: la décapitation de " l'icône » Zachariadis fut perçue par lui et, bien évidemment par ses disciples, comme l'amorce d'un long processus d'asservissement, d'assujettissement et de soumission de soi. C'était comme une excommunication totale tissée par "l'ordre soviétique » et destinée à faire disparaître non seulement leurs luttes, mais surtout leur dignité " communiste", leur code axiologique et moral. Ce fut le début d'une lutte acharnée entre le PCUS et la « vieille garde » du KKE.

Les troubles du PCUS eurent une résonance directe dans le Bureau politique du KKE, qui dépendait plus que jamais des Soviétiques. Citons un exemple caractéristique : comme on le sait, en juin 1957, le Présidium du Soviet suprême, à l'initiative de Georgui Malenkov, Viatcheslav Molotov, Mikhaill Pervoukhine, Andreï Sabourov, Lazare Kaganovitch, Kliment Vorochilov et Nikolaï Boulganine, réclama la démission de 
Nikita Khrouchtchev. Mais le Comité central, réuni grâce au soutien inconditionnel du maréchal Guergui Joukov, se transforma en arbitre du conflit qui divisait le BP (Bureau politique). Ainsi le CC remporta-t-il une victoire significative sur l'ancienne garde stalinienne en ratifiant en même temps les acquis du $\mathrm{XX}^{\mathrm{e}}$ Congrès ${ }^{2}$. Face à ces événements, le BP du KKE adopta la résolution suivante :

Résolution du Bureau politique du CC du KKE,

Le groupe «antiparti» de Kaganovitch, Malenkov et Molotov attaché à des conceptions périmées et erronées, tout en se livrant à une activité fractionnelle antiparti, est digne de la sanction la plus sévère. Et cela, parce qu'il a violé le plus haut principe léniniste de l'unité du Parti et a contrecarré les projets de son développement [...].

6 juillet 1957

Le BP du CC du KKE ${ }^{3}$.

6 Cette résolution n'était en réalité qu'une copie mot à mot de la décision du CC du PCUS qui, après avoir annulé le vote du Présidium, dénonça et condamna «les activités fractionnelles du groupe antiparti ${ }^{4} »$. Cette façon de réagir devint progressivement la norme de conduite principale du BP. En effet, pendant la période 1956-1962, la seule stratégie approuvée par le KKE fut celle qui avait reçu le consentement explicite du Kremlin. Les cadres supérieurs du KKE, dont l'autorité s'étendait théoriquement à tous les domaines relatifs à la Grèce, voyaient leur fonction découpée en plusieurs parties et leur influence réduite par une série de décisions des instances de Moscou. Leur rôle principal consistait plutôt en une fonction administrative qu'en un travail politique réel. Il en résultait parfois un rassemblement hétéroclite des forces du KKE sans aucune homogénéité politique entre elles: l'essentiel restait que l'action des communistes grecs fût toujours compatible avec les orientations principales de la politique extérieure du Kremlin. Ceux qui n'obéissaient pas à cette règle étaient exclus du Parti. Les cadres qui se disputaient le pouvoir au sein de la direction du KKE y étaient perpétuellement encouragés par les divers groupes antagoniques du PCUS. Ainsi, tout comme dans certaines démocraties populaires, les clivages historiques du PCUS se répercutaient directement dans les rangs du KKE. C'est ici que nous pouvons détecter le fond du problème : la crise de la direction du KKE apparut de manière manifeste au lendemain de l'éclatement des conflits, plus ou moins dissimulés, au sein du PCUS. Dès lors, le KKE était divisé en plusieurs factions antagoniques qui se référaient sans cesse à la suprématie « naturelle » de l'URSS.

\section{La critique de Ceaușescu : des émeutes de Tachkent (1955) à la scission du KKE (1968)}

7 Après la défaite de l'AD au cours de la guerre civile grecque, les communistes furent divisés en deux groupes principaux: la population civile fut répartie entre les démocraties populaires, les divisions militaires de l'AD furent transférées en URSS, à Tachkent. Les émeutes qui eurent lieu à Tachkent en 1956 eurent des conséquences dramatiques : à la suite d'une série d'actes de vengeance entre les ex-partisans de l'AD, plusieurs condamnations, des peines de réclusion furent prononcées. Certains membres de la Collectivité de Tachkent goûtèrent donc à la prison.

8 Le rejet du projet de programme du KKE par les Soviétiques en 1954 marqua le commencement d'un long processus qui se termina par l'éviction de Nikos Zachariadis en février 1956. Le clivage politique et les étapes de la transition entre l'ancienne forme 
du communisme et son avatar réformiste ont marqué l'histoire du PCUS puis, après les émeutes des communistes grecs à Tachkent ${ }^{5}$, celle du KKE. Cette politique soviétique se refléta dans la politique du KKE et déstabilisa ses appareils organisationnels à Tachkent. Panos Dimitriou, un des protagonistes principaux de ces événements parle ouvertement de l'ingérence du PCUS à Tachkent :

Les disciples antistaliniens de l'équipe de Khrouchtchev voyaient d'un bon œil ces points de vue [la lutte contre Zachariadis et son passé] et favorisaient notre lutte. C'est-à-dire : nous étions dans le même camp et ils nous ont entourés de leur bienveillance $[. . .]^{6}$.

Ce témoignage fut confirmé par une autre source: quelques années plus tard, Nicolae Ceauşescu, à l'occasion d'une entrevue qui s'est déroulée le 3 avril 1968, entre le Comité central du Parti communiste roumain (PCR) et les représentants du CC du KKE, en particulier avec Kostas Koliyannis et Leonidas Striggos, membres du CC du KKE, confirma complètement l'hypothèse de l'ingérence de l'URSS et des partis «frères » dans les affaires intérieures du KKE :

[...]. Je vous ai dit tout à l'heure [...], dit Ceauşescu, qu'un jour il faudra dire pourquoi on s'est ingéré dans les affaires intérieures de votre Parti en 1956, parce que je suis sûr que lorsque le Parti communiste arrivera au pouvoir en Grèce, il nous blâmera pour cela, et il arrivera à la conclusion qu'on a mal réagi, comme, à l'heure actuelle, on le dit, nous-mêmes : dans le passé, notre Parti a mal réagi [face à cette question] [...] $]^{7}$.

Comment expliquer ce revirement de la politique roumaine face à une question, plus ou moins internationale, orchestrée par «le grand frère soviétique»? Dans les années 1960, la politique roumaine face à l'URSS bouleversa les calculs politiques des Occidentaux. Nicolae Ceauşescu fut perçu en Occident comme un leader soucieux d'indépendance et prêt à rompre ses relations politiques avec l'URSS. Le rapprochement spectaculaire de la Roumanie avec la Chine inquiétait les Soviétiques. Au début de l'année 1967, le conflit sino-soviétique franchit un nouveau palier dans la tension: après le déclenchement de la "révolution culturelle» en Chine, les Soviétiques ne pouvaient plus investir politiquement dans une Conférence éventuelle qui aurait pu contribuer à l'unité du camp socialiste. En janvier 1967, le Drapeau rouge, organe officiel du Parti communiste chinois, accusa les « révisionnistes modernes » de Moscou d'avoir donné leur appui à la " clique antiparti » en s'ingérant dans les affaires intérieures de la République populaire de Chine. Le 9 janvier 1967, dans ses «Thèses sur le cinquantième anniversaire de la prise du pouvoir", le CC du PCUS évalua les événements en Chine en qualifiant la « révolution culturelle» de tentative visant à substituer au marxisme-léninisme authentique une "phraséologie et des dogmes pseudo-révolutionnaires ». Au mois de février, plusieurs manifestations eurent lieu à Pékin et à Moscou. Les manifestants se réunirent devant l'ambassade de l'URSS à Pékin et devant l'ambassade de Chine populaire à Moscou. Le danger d'un conflit interne au monde communiste, entre les deux géants du camp socialiste, était une possibilité qui menaçait la stabilité du «système communiste ». Face à ce conflit, la position adoptée par Bucarest fut considérée par Moscou comme une initiative contraire aux intérêts soviétiques. Voyons les faits de plus près: en février 1967, Ceauşescu donna à la délégation du KKE des informations importantes sur l'étendue du conflit sino-soviétique :

[...]. Les jours où il y a eu des manifestations devant l'ambassade soviétique à Pékin et l'ambassade chinoise à Moscou, nous étions inquiets [...] face à la possibilité d'une rupture des relations diplomatiques entre la Chine et l'Union soviétique. Nous 
avons décidé d'envoyer aux camarades chinois et aux camarades soviétiques un message faisant preuve de notre inquiétude tout en exprimant notre position: [demander aux deux Partis] de ne pas procéder à des actions qui aboutiraient à une situation [de non-retour]. Nous avons soulevé la question de la prise de mesures assurant la mise en place des procédures régulières de la diplomatie officielle. Je vous prie de garder ces informations [pour vous-mêmes], car il s'agit d'une question strictement interne qui ne sera en aucun cas divulguée. Mais je vous ai donné ces informations afin de vous tenir au courant du résultat de cette initiative. Notre ambassadeur a été reçu par les camarades chinois, par le ministre des Affaires étrangères Chén Yì. Nous avons envoyé un message à Zhou Enlai et à Mao Zedong ainsi qu'à l'Union soviétique, aux camarades Brejnev et Kossyguine. Chén Yì a naturellement dit qu'il faut blâmer les camarades soviétiques et que le message sera transféré à Mao Zedong et à Zhou Enlai [...]. Notre ambassadeur a été aussi reçu par les camarades soviétiques, par Andropov: il a dit qu'il transférera notre message aux camarades Brejnev et Kossyguine et que la responsabilité repose sur le côté chinois. Il a dit à la délégation roumaine son avis personnel en insistant sur ceci : le fait que le message fut envoyé tant aux Chinois qu'aux Soviétiques, sans condamner les Chinois, met en évidence que, pour les Roumains, les Soviétiques sont sur le même pied d'égalité que les Chinois. Selon lui, la responsabilité repose sur le côté chinois [...] et, vu sous cet angle, le message n'a pas été bien accueilli par le PCUS. Certes, notre ambassadeur a contesté cette appréciation. Cela s'est produit le 8 février au cours des manifestations $[. . .]^{8}$

11 Ceauşescu s'efforça de mettre en cause la rhétorique officielle défendue par Moscou. Cette « dénonciation » du «style » historique de la direction du PCUS mit en évidence la politique de Bucarest qui revendiquait de facto son autonomie relative à l'égard de Moscou. Elle prit la forme d'une stricte neutralité vis-à-vis des problèmes internes du camp socialiste. De manière significative, cette critique pouvait, sous certaines conditions, bouleverser de fond en comble le principe de dépendance absolue du KKE à l'égard du PCUS. L'argumentation suivante de Ceauşescu ne laissait pas indifférents certains membres du BP du KKE tels que Dimitrios Partsalidis (dit souvent Mitsos, et cité comme M. Partsalidis) et Panos Dimitriou (également membres du secrétariat du Comité central du Parti grec), qui avaient déjà commencé à avoir des doutes en ce qui concerne la politique internationale soviétique Voyons les dires intéressants du leader roumain :

[...]. Que montrent d'après Marx la pratique du mouvement communiste international et celle du mouvement ouvrier? Les problèmes sont affichés publiquement et des points de vue sont échangés. Ainsi, une ligne spécifique et un concept idéologique étaient créés, sans conduire à la fusillade de ceux qui exprimaient d'autres points de vue, même si leurs critiques étaient des critiques acerbes. Il est vrai que Marx n'était pas le président d'un gouvernement, je dis cela comme une plaisanterie, mais je suis convaincu que même s'il avait été président du gouvernement, il n'aurait pas agi de la même façon. À titre d'exemple : à l'époque de Lénine, pendant la période où le PCUS luttait en vue de prendre le pouvoir, les débats étaient longs jusqu'à l'adoption définitive des thèses par le PCUS. Ainsi a-t-il abouti à la cristallisation d'une conception [politique] correcte. C'est pourquoi nous pensons qu'un débat est requis, mais dans le contexte d'une analyse spécifique des problèmes. Nous ne pouvons accepter ni réfuter une opinion en fonction de notre propre opinion, considérant celui qui n'est pas d'accord avec nous comme quelqu'un qui s'oppose à nous. Parce que cela nous amène précisément à ce que faisait l'Église, aussi bien orthodoxe que catholique: au lieu d'analyser scientifiquement [les faits] nous arrivons à la confirmation d'un dogme auquel tous doivent croire, et celui qui n'y croit pas est considéré comme hérétique. Est-ce possible de dire que le vrai marxisme-léninisme est constitué par ce que [...] [dit un seul Parti] ? Je n'ai vu ça ni chez Marx, ni chez Engels, ni chez Lénine [...] ${ }^{9}$. 
12 La politique de non-ingérence de la Roumanie dans les affaires intérieures des autres partis « frères » était due, selon l'argumentation officielle du PCR, à une réévaluation de l'histoire soviétique. La question de la sincérité (certes discutable) de ces thèses eut un écho considérable dans la direction du KKE. Elle laissait entendre par là que les courants socialistes centrifuges qui ne mettaient pas en péril la politique extérieure de la Roumanie pouvaient être désormais tolérés par Bucarest. Pour les communistes grecs, les dires du leader roumain revêtirent un sens évident :

[...]. Vous connaissez, dit Ceauşescu, l'histoire du PCUS, les luttes [internes] qui datent de l'époque de Lénine et la façon dont elles ont été résolues: vous vous rappelez les problèmes avec Trotski et Boukharine. Lénine a résolu ces problèmes dans un esprit qui visait à maintenir le contexte du renforcement et de l'unité [du Parti]. En 1917, vous vous rappelez que Zinoviev et Kamenev furent accusés publiquement parce qu'ils avaient trahi la révolution, mais ils sont restés au pouvoir. Ainsi, Lénine a résolu pratiquement et publiquement ce problème. Par la suite, tout n'a pas été résolu ainsi : vous vous rappelez les procès qui ont eu lieu [en URSS] et les révélations du PCUS en 1956 à ce sujet? [Les Chinois] comment devaient-ils réagir ? Commencer à condamner l'Union soviétique ou procéder à ce que nous avons fait à l'époque, défendre l'Union soviétique ? En 1937, 1938 et 1939, quand ces procès eurent lieu, nous avons défendu l'Union soviétique, au moment où les choses ne se sont pas résolues de manière démocratique [mais] de manière contraire aux règles du Parti. Pourquoi dis-je tout ça? Parce que nous sommes inquiets face aux faits qui se déroulent en Chine. Nous devrions comprendre que la solution n'est pas de commencer à blâmer la Chine en aggravant les choses. Et si nous pouvons aider à trouver une solution, cela signifie : ne pas s'ingérer [...] dans les affaires intérieures des autres Partis $[. . .]^{10}$.

Ces thèses roumaines envenimèrent davantage les luttes internes des communistes grecs qui voyaient apparaître les premières "fissures" tangibles dans le camp du « socialisme réel ». Plus concrètement, l'année 1967 marqua un tournant très important dans les relations des membres du KKE : en dehors du fait que les dirigeants du Parti se disputaient le pouvoir de manière de plus en plus ouverte, la dictature militaire (avril 1967 -juillet 1974) força plusieurs militants à s'installer dans les pays de l'Europe occidentale. La dégradation progressive de l'image de l'URSS dans le monde, à la suite du conflit sino-soviétique, entraîna un flot de contestations contre toute tentative d'extériorisation de la stratégie soviétique dans les Partis communistes occidentaux. L'événement qui servit de catalyseur à ce tournant fut le théorème de l'eurocommunisme. Cette réalité faisait suite à une réorientation complète de la politique de certains Partis communistes occidentaux, à l'instar du PCI, succédant à la politique « du monolithisme » qui avait plongé ces Partis dans un état de dépendance idéologique presque complet. La dictature militaire en Grèce aboutit à l'expatriation des militants de la Gauche qui, d'une manière ou d'une autre, allèrent dans les pays occidentaux, en France, en Angleterre, et surtout en Allemagne de l'Ouest, afin d'éviter l'emprisonnement et de lutter pour leurs idées. L'installation des réfugiés politiques grecs dans ces pays facilita leur rapprochement avec les divers courants de l'eurocommunisme. Mais quelle est la relation entre la scission du KKE en 1968 et l'eurocommunisme? Quel était le rôle de Bucarest et son attitude face à la crise du KKE ? 


\section{Le Parti communiste roumain (PCR) et la scission du Parti communiste de Grèce (KKE)}

14 Le contexte historique était polarisé par le conflit sino-soviétique et la nouvelle orientation de la politique extérieure soviétique qui abandonnait le principe de la coexistence pacifique dans les lieux géostratégiques périphériques du globe où la compétition entre les deux superpuissances (États-Unis/URSS) devenait plus vive que jamais. Dans ce contexte, la scission du KKE en 1968 faisait allusion aux vieux axiomes soviétiques défendus par Khrouchtchev (pluralisme des voies amenant au socialisme, coexistence pacifique, etc.). À cela, il faut ajouter le «maintien de bonnes relations » entre l'Union soviétique et la Grèce des colonels qui, selon le Kremlin, ne signifiait " aucune réconciliation idéologique avec le régime ».

Kostas Koliyannis devint Premier secrétaire du KKE après l'éviction de Zachariadis. Dimitrios Partsalidis, l'un des anciens membres du Parti accusé de «fractionnisme » à partir de 1956, fut à nouveau membre du Bureau politique et du Secrétariat du KKE et l'un des interlocuteurs privilégiés du PCUS après la destitution de Zachariadis et l'arrivée de Khrouchtchev au pouvoir en Union soviétique. Ces deux personnages se disputaient le pouvoir au sein du Parti. Les racines de leur conflit étaient dues à l'histoire récente du KKE. Après la fin de la guerre civile, en 1951, un nouveau parti, la Gauche démocratique unifiée (EDA), avait vu le jour en Grèce. Entre-temps, le gouvernement d'Athènes avait décrété l'abolition juridique, c'est-à-dire l'interdiction, du Parti communiste dès 1947. En apparence, de 1964 à 1968, la querelle entre Koliyannis et Partsalidis concernait les formes de réorganisation des forces communistes en Grèce, Koliyannis voulait que les communistes luttent en faveur de la légalisation de facto du KKE tandis que Partsalidis favorisait plutôt l'alliance avec l'EDA, à laquelle participaient aussi des forces plus «centristes" à tendance socialiste. Néanmoins, au fond, ce duel reflétait les différentes stratégies soviétiques par rapport à la Grèce et la dépendance absolue des communistes grecs à l'égard du Kremlin ${ }^{11}$.

Les opinions de Partsalidis et de Dimitriou - approuvées par Zisis Zografos, membre de la direction du KKE -, en matière d'organisation du KKE, avaient été explicitement dénoncées par la direction soviétique au cours du $12^{\mathrm{e}}$ Plénum qui se tint à Budapest du 5 au 15 février 1968. La lettre des Soviétiques stipulait :

Chers camarades,

Nous avons soigneusement étudié les lettres du camarade Partsalidis envoyées le 10 novembre 1967 et le 18 janvier 1968, au CC du PCUS. Considérant que les problèmes soulevés par le camarade Partsalidis sont une affaire intérieure qui concerne exclusivement votre Parti, le CC du PCUS ne voit pas l'intérêt d'analyser sa position particulière en matière de questions d'organisation, face auxquelles le Comité central du KKE s'est déjà exprimé en adoptant une décision collective. Pour la même raison, nous ne pensons pas qu'il soit approprié d'accueillir au CC du PCUS le camarade Partsalidis en vue de procéder à une discussion qui porterait sur ces affaires.

Comme vous le savez bien, lors des successives réunions d'amitié entre les représentants de nos Partis, qui ont toujours eu lieu dans une atmosphère de compréhension mutuelle et sincère [...], le CC du PCUS s'est fermement exprimé en faveur de la politique et de la tactique adoptées par le CC du KKE [...].

Guidés par les relations de sincérité et de confiance établies entre nos deux Partis, nous avons échangé, à la demande des camarades grecs, des points de vue et des avis sur des questions qui furent abordées par le $8^{\mathrm{e}}$ et le $10^{\mathrm{e}}$ Plénum du CC du KKE. 
D’après nous, la vie a confirmé la justesse de la ligne politique adoptée par le CC, lors $\mathrm{du} 8^{\mathrm{e}}$ et du $10^{\mathrm{e}}$ Plénum du KKE. Cela semble particulièrement clair maintenant, à la lumière des récents événements tragiques en Grèce, provoqués par la mise en place d'une dictature militaro-fasciste dans le pays [...] $]^{12}$.

17 Face à cette intervention, la «troïka », Partsalidis, Dimitriou et Zografos, prit l'initiative de défendre le passé récent du Parti de 1956 à 1968 en proclamant, dans une lettre radiodiffusée, son attachement aux principes du XX Congrès du PCUS et en accusant le «putsch» du $12^{\mathrm{e}}$ Plénum de «restaliniser» le Parti en souplesse. Voici le contenu de cette lettre :

[...]. Ainsi, 12 ans après le $6^{\mathrm{e}}$ Plénum du Comité central de 1956, le camarade Koliyannis et son groupe, représentant le conservatisme et la stagnation dogmatique, tentent-ils d'achever le parcours d'éloignement de l'esprit du $6^{\text {e }}$ Plénum et le retour au régime politique anormal du passé qui a engendré tant de maux au KKE et au mouvement populaire de notre pays ${ }^{13}$.

18 Persécutés par le KKE, qui avait déjà acquis l'aide multiforme de Moscou, les « dissidents » n'avaient plus qu'une solution : le recours à l'aide du Parti roumain. Les autorités roumaines leur octroyèrent une aide "camouflée » qui, à ce stade de la bataille interne, fut inappréciable. Le dialogue suivant est significatif à cet égard :

[...]. Le camarade Zografos :

- Si Koliyannis n'avait pas une aide de l'extérieur, il n'existerait pas aujourd'hui.

C'est la vérité [...].

Le camarade Nicolae Ceauşescu :

- Que voulez-vous que fasse la Roumanie ? Et je sais une chose : vous ne devriez pas adopter une ligne [politique] reconnaissant l'existence d'un nouveau Comité central. Ce n'est pas bon.

Le camarade Zografos :

- Nous l'avons clairement indiqué dans notre lettre. Nous voudrions avoir la capacité d'aller dans d'autres pays.

Le camarade Nicolae Ceauşescu :

- Que pouvons-nous faire?

Le camarade Zografos :

- Des passeports. Cela aurait une signification.

Le camarade Nicolae Ceauşescu :

- Je vous ai dit que des passeports vous seront délivrés ${ }^{14}$.

19 La création d'un nouveau Parti était-elle directement due à l'aide roumaine ? Il ne semble pas. L'idée d'un nouveau Parti indépendant avait été énoncée depuis longtemps par certains membres de la Collectivité de Tachkent. Comment pouvons-nous expliquer ces événements? Ainsi que l'avait écrit dans son journal, en mars 1968, l'un des plus ardents partisans de ce mouvement contestataire, Mpeikos Georgoulas, le correspondant du journal d'Avgi à Moscou :

[...]. Les trois camarades [M. Partsalidis, Z. Zografos et P. Dimitriou] portent une grande responsabilité de la période qui a succédé au $6^{\mathrm{e}}$ Plénum de 1956, et qui a conduit mathématiquement à une recrudescence de la situation. Ils ont toléré, ils n'ont pas vu, ils ont contribué [à ce qui s'est passé]. Ils ont réagi lorsque ce groupe [K. Koliyannis et le BP du KKE] a foulé aux pieds leur bonne foi, quand ils leur ont mis le couteau sous la gorge. Telle est l'amère vérité : pour tous les trois. Quand le couteau du manque de démocratie, des abus et de la violation de nos principes coupait la gorge des autres, cela ne faisait, bien entendu, aucun mal. Ils restaient calmes. Certes, cela ne doit pas nous conduire au nihilisme. Il faut en tirer la leçon nécessaire. [Il faut] dire au Parti: les personnes qui dirigent le Parti doivent comprendre qu'ils ne peuvent pas avoir seulement des droits, mais qu'ils assument, par nous tous, de lourdes responsabilités. On doit, avant tout, élever le sens de la 
responsabilité des gens qui dirigent le Parti. On souffre de son absence. Parallèlement, tous les membres $\mathrm{du}$ KKE, nous devrons faire sentir nos responsabilités : arrêter de jouer le rôle «d'imbéciles » [...] et parler avec franchise et courage. Chaque membre du Parti, en levant la main pour approuver ou repousser une décision, une action, etc., doit penser à sa responsabilité vis-à-vis du peuple grec. Si tel n'est pas le cas, il vaut mieux que ce membre renvoie sa carte du

Parti, sinon on peut penser qu'il la garde pour en tirer profit [... $]^{15}$.

Ce témoignage inédit est suffisamment parlant : la dépendance était diachroniquement le facteur de cohésion de la direction du KKE. En réalité, 1968 n'a pas été le moment d'une véritable "révolution culturelle", ou d'une insurrection hérö̈que contre le "soviétisme ", mais le moment où le "couteau » du limogeage politique "a été mis sous la gorge " des trois protagonistes principaux qui revendiquèrent, à la dernière minute, leur propre émancipation, ou leur propre sauvetage politique.

\section{Les communistes grecs, leur scission et les Roumains}

21 En 1968, les communistes grecs ne considéraient plus l'URSS comme le pilier central de la révolution mondiale. En effet, le désarroi de 1956 avait laissé son poison sécessionniste et les membres de la diaspora du KKE étaient restés relativement impassibles face aux émeutes tragiques de Tachkent. Leur survie personnelle et la protection de leur famille étaient leur préoccupation première. La crise fut manifestement l'effet d'une crise plus générale: celle de l'aliénation du «socialisme réel». En d'autres termes, la crise du mouvement communiste mondial fut aussi reflétée par la scission du KKE. Tout débat idéologique ultérieur lié, d'une part, à la dispute des «marxistes-léninistes » contre les « opportunistes ", thèse défendue par le KKE, et de l'autre, à la lutte des "forces rénovatrices » contre "les dogmatiques » prosoviétiques, axiome soutenu par le Parti communiste "de l'intérieur", ne fut qu'une réminiscence idéologique produite par deux théories constructivistes dérivées plutôt du mythe post-sécessionniste du KKE, où chacun des porteurs principaux semblait éprouver le besoin de se justifier, que de la réalité objective.

L'eurocommunisme, censé être à l'origine de la scission, a influencé la base - et non la direction qui prit l'initiative de la scission - du Parti communiste de l'intérieur tardivement, a posteriori. En dehors du fait que Partsalidis, Dimitriou et Zografos n'étaient que des hommes politiques de terrain sans aucun lien organique avec la "théorie », deux sources mettent en lumière les traces des liens du PC de l'intérieur avec l'eurocommunisme. La première est ici une lettre que, le 21 août 1968, Partsalidis envoya au Comité central du PCR :

Au Comité central du Parti communiste roumain

Chers camarades,

À propos de la situation extrêmement critique créée après l'entrée des forces armées de cinq pays socialistes dans la République socialiste de Tchécoslovaquie, nous avons besoin de vous contacter pour vous exposer la position que nous adoptons à l'égard de ces événements tragiques et de demander votre opinion sur certaines questions qui nous préoccupent directement [... $]^{16}$.

Comme on le sait, en 1968, Nicolae Ceauşescu avait tenu tête aux Soviétiques en s'opposant à l'invasion de Tchécoslovaquie et, chose encore plus grave, en refusant d'intervenir à Prague. Cette politique audacieuse avait certainement réussi à réunir autour de sa stratégie " hérétique » un large consensus qui dépassait l'horizon de ses ambitions nationales. Dans ces circonstances historiques, les communistes grecs 
proroumains, nommés " de l'intérieur ", suivirent son projet après avoir manifesté leur désaccord avec Moscou. En effet, le 5 septembre 1968, le "Bureau de l'intérieur " s'aligna sur les thèses roumaines et dénonça l'invasion soviétique. C'est le moment où les liens politiques entre "les dissidents" et les Soviétiques se coupèrent définitivement. De surcroît, l'aide octroyée par Bucarest aux «communistes de l'intérieur » était significative, comme en témoigne la lettre suivante de Nikos Kentros, membre du CC du PC de l'intérieur :

Note

Au Département des relations internationales du Parti communiste roumain

Camarade Ghizela,

Chers camarades,

Grâce à votre aide inappréciable, nous avons acheté jusqu'à présent par le biais de «Virement» [transfert, avec subside de la Roumanie] une série d'anciens objets populaires par des magasins correspondants.

Ces objets nous ont donné la possibilité d'ouvrir un magasin spécial en Belgique.

En exploitant ces objets, nous avons eu l'occasion d'obtenir une source de revenus pour les besoins du Bureau de l'intérieur en Grèce.

Cette fois-ci, nous vous prions de nous aider à acheter certains vieux meubles par le biais de «Virement» et à les envoyer par votre organisation du commerce extérieur « Libri ».

Le besoin d'achat de ces meubles est aussi expliqué par le fait que les vieux articles d'art ne sont pas vendus par consignation du fait qu'ils ne sont pas contrôlés par le Musée.

2. X. 1971

Salutations fraternelles

Pour le CC du PC (de l'intérieur)

N. Kentros ${ }^{17}$.

Il s'ensuit que les Roumains veillèrent à la survie économique de leurs protégés grecs par les voies les plus invraisemblables. Parallèlement, Ceauşescu visait à réformer l'économie de son pays en jouant «l'honnête courtier » entre l'Est et l'Ouest. Moscou n'était pas forcément contre cette tendance centrifuge. Dans la mesure où les Soviétiques refusaient de concéder à la Roumanie un statut important, à part entière, au sein du pacte de Varsovie, l'Union soviétique n'avait rien à craindre du côté roumain. Comme l'a souligné François Fejtö :

Dans les années 70, la relative insubordination de la Roumanie favorisait autant l'image du camp socialiste et de l'URSS que la «libéralisation» pratiquée parallèlement par les autorités polonaises ou hongroises. Les liens entretenus par le régime de Ceauşescu avec bon nombre de pays d'obédience marxiste-léniniste et d'organisation de libération nationale dans le tiers-monde facilitaient le développement de leurs contacts avec l'URSS là où une responsabilité directe de Moscou aurait pu être mise en cause. Last but not least, le développement des échanges commerciaux avec les pays occidentaux a permis le transit par la Roumanie d'équipements et de technologies autrement inaccessibles à l'Union soviétique ${ }^{18}$.

La création du KKE de l'intérieur n'était pas l'acte qui conduirait à un mouvement de contestation populaire avec comme objectif la chute du régime d'Athènes; la survie du KKE dans les démocraties populaires et l'URSS, sous la mainmise contraignante des Soviétiques, ne renvoyait pas non plus à une lutte de fait contre la junte militaire des colonels. Au contraire, le PCR contrôlait la lutte antidictatoriale des communistes de l'intérieur, et, par ce biais, les Soviétiques avaient toujours un droit de regard sur les 
activités antidictatoriales tant du KKE que du KKE de l'intérieur; il s'agit d'un « contrôle par procuration ».

En second lieu, «l'eurocommunisme» du KKE de l'intérieur découla plutôt des circonstances politiques des années 1970 que de la volonté des communistes de l'intérieur de se débarrasser "des rouilles du dogme» soviétique; ce fut une perspective à atteindre plus qu'un projet théorique résolu. Comme l'a écrit Zisis Zografos, le 26 janvier 1971, au Comité central du PC de l'intérieur :

Le 22 janvier 1971, j'ai rencontré à l'aéroport de Rome le camarade Segre, le jeune responsable $\mathrm{du}$ département des relations internationales $\mathrm{du}$ CC du Parti communiste italien (il attendait une délégation étrangère d'un parti frère). On se connaissait bien avant la scission [...]. Il a également posé des questions sur la situation actuelle dans le KKE. Il m'a dit qu'ils voulaient avoir un contact plus effectif avec nous. Pour répondre spécifiquement à la question de la meilleure préparation d'une manifestation plus générale au printemps concernant la mobilisation de forces plus larges, en vue de lutter contre le régime actuel en Grèce. Il m'a proposé de lui rendre visite à son bureau quand je vais revenir à Rome ${ }^{19}$.

Dans ces conditions, le PC de l'intérieur, entièrement prisonnier entre les objectifs mondiaux soviétiques et les intérêts périphériques roumains, cherchait désespérément à trouver des appuis politiques. L'appropriation, après coup, de l'eurocommunisme de la part des communistes grecs «de l'intérieur» fut le résultat de la contingence historico-politique des années 1970, et non le point de départ d'une lutte libératrice contre la « soumission soviétique ».

\section{Conclusion}

La transmission de la tradition historique, exprimée en l'occurrence par la narration historiographique des deux Partis grecs, établie après la scission du KKE, entrava la transmission de la connaissance historique. Les uns disaient que «les rénovateurs s'opposèrent aux dogmatiques " tandis que les autres insistaient sur la cause juste du «marxisme-léninisme» qui, de bon droit, luttait contre «l'opportunisme». Nous pouvons dire que les deux interprétations sont, du point de vue historique, fausses. Cela ne signifie pas que, du point de vue idéologique, ces deux "explications " ne puissent avoir des effets concrets : tant que les collectivités existent, les idéologies se répercutent dans le temps et dans l'espace, mais, et sans vouloir insinuer que l'histoire soit une science entièrement exempte de toute référence à une conception du monde, ces deux perceptions, historiquement parlant, sont fondamentalement erronées.

En 1949, les communistes grecs ont dû faire face à une défaite stratégique dont les séquelles allaient décomposer leur unité ainsi que leurs perspectives révolutionnaires, au moins à brève échéance. Ensuite, le XX ${ }^{e}$ Congrès du PCUS (1956) a imposé au sein du KKE la «dézachariadisation» du Parti. La première conséquence en fut la désintégration de la base du Parti qui, en dépit des théories confuses liées à la nature démocratique des "Partis de type nouveau», avait été largement influencée par les luttes et les symboles du passé. L'éradication soviétisée de ces symboles, les décrets prosoviétiques, transformant les icônes révolutionnaires du passé en figures "contre-révolutionnaires" et "antisoviétiques », créèrent les conditions qui permirent l'émergence d'une série de luttes et d'escarmouches politico-idéologiques, et scindèrent en plusieurs factions antagoniques les collectivités des réfugiés politiques comme les militants qui se trouvaient dans les prisons de Grèce. 
D'un autre côté, cette période posa les jalons d'un humanisme diffus. En 1968, sous la pression du changement progressif de la politique extérieure de l'URSS et des problèmes du camp socialiste, ce courant humaniste se scinda en deux : le courant apologétique s'aligna sur la politique du PCUS; le courant centrifuge chercha à se cramponner à la politique de Bucarest pour subsister politiquement et économiquement. Dans les deux cas, leur dépendance était absolue. L'axe moscovite et l'axe roumain n'étaient que la preuve de la défaite définitive des communistes grecs dans cette conjoncture historique précise, polarisée par la guerre froide. En d'autres termes, les problèmes du camp socialiste et ceux de l'URSS eurent leur écho au sein du KKE. Aussi, la scission du KKE contenait-elle en germes les graves potentialités de la dissolution de l'URSS, qui s'avéra incapable - sauf lorsqu'elle parvint à contrebalancer les effets d'une crise par le recours à la force armée, comme ce fut le cas de l'invasion d'août 1968 à Prague -, d'exercer politiquement un pouvoir de dissuasion susceptible d'empêcher la scission du KKE.

\section{BIBLIOGRAPHIE}

\section{Archives}

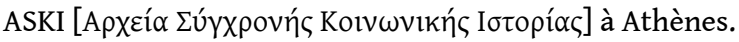

A.N.I.C. (Arhivele NaŢionale Istorice Centrale) à Bucarest.

\section{Ouvrages}

FEJTÖ François (avec la collaboration d'Ewa KULESZA-MIETKOWSKI), 1992, la fin des démocraties populaires, les chemins du post-communisme, Paris : Seuil.

KKE, 2008, H $12^{\eta}$ o

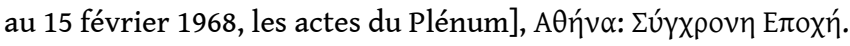

PAPADATOS Nikos, 2016, les communistes grecs et l'Union soviétique : Histoire de la scission du Parti communiste de Grèce (1949-1968), Paris : L’Harmattan, coll. « Chemins de la Mémoire ».

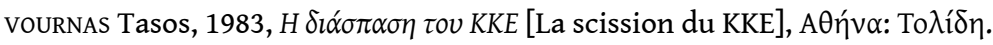

WERTH Nicolas et MOULLEC Gaël (éd.), 1994, Rapports secrets soviétiques : la société russe dans les documents confidentiels, 1921-1991, Paris : Gallimard.

WERTH Nicolas, 2001, Histoire de l'Union soviétique : de l'Empire russe à l'Union soviétique, 1900-1990, Paris : PUF.

\section{NOTES}

1. François Fejtö (avec la collaboration d'Ewa KULESZA-MIETKOWSKI), 1992, la fin des démocraties populaires, les chemins du post-communisme, Paris : Seuil, p. 64. 
2. Sur ce sujet, voir Nicolas WERTH, 2001, Histoire de l'Union soviétique : de l'Empire russe à l'Union soviétique, 1900-1990, Paris: PUF, p. 436-442, ainsi que Nicolas WERTH et Gaël MOULLEC (éd.), 1994, Rapports secrets soviétiques: la société russe dans les documents confidentiels, 1921-1991, Paris : Gallimard, p. 612-623.

3. Archives d'histoire sociale contemporaine (ASKI), KKE, K. 384, $\Phi=20 / 34 / 50$. Document en grec [c'est nous qui traduisons].

4. Nicolas WERTH, 2001, Histoire de l'Union soviétique, op. cit., p. 441.

5. Sur ce sujet, voir Nikos PAPADATOS, 2014, l'histoire de la scission du Parti communiste de Grèce: 1937-1968, thèse de doctorat, Université de Genève, Faculté des lettres, Département d'histoire générale, Unité d'histoire contemporaine. Nikos PAPADATOS, 2016, les communistes grecs et l'Union Soviétique: Histoire de la scission du Parti communiste de Grèce (1949-1968), Paris : L’Harmattan, coll. « Chemins de la Mémoire ».

6. Journal Eleftherotypia, 3 avril 1980.

7. Arhivele NaŢionale Istorice Centrale (A.N.I.C.), Fonds C.C al PCR - Secţia relaţii ext., dos. 47/1968, f. 14. Archives du Comité central du Parti communiste roumain. Document en roumain dactylographié. Conversations sténographiées entre Nicolae Ceauşescu et Kostas Koliyannis, Apostolos Grozos et Leonidas Striggos (3 avril 1968).

8. A.N.I.C., Fonds C.C al PCR - Secţia relaŢii ext., dos. 9/1967, ff. 31, 32.

9. Ibid., f. 36 .

10. Ibid., ff. 33, 34 .

11. Pour de plus amples informations sur ces questions, voir Nikos PAPADATOS, 2016, les communistes grecs et l'Union Soviétique: Histoire de la scission du Parti communiste de Grèce (1949-1968), op. cit.

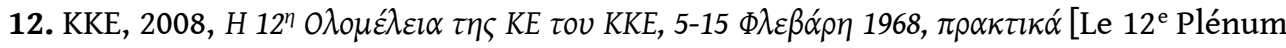

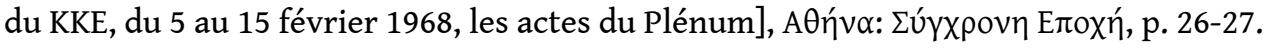

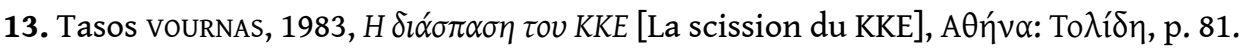

14. A.N.I.C., Fonds C.C al PCR - SecŢia relaţii ext., dos. 48/1968, f. 7. Conversation sténographiée entre le secrétaire général du PCR, Nicolae Ceauşescu et les camarades Mitsos Partsalidis, Zisis Zografos et Panos Dimitriou, membres du BP du PC grec, 4 avril 1968. Document en roumain, f. 23 [souligné par nous].

15. Journal inédit de Mpeikos Georgoulas, 31 mars 1968, manuscrit.

16. ASKI, Archives du KKE, K. 382, 20/32/127, f. 1.

17. ASKI, Archives du KKE, K. 382, 20/32/183, f. 1 [souligné par nous].

18. François FEJTÖ, 1992, la fin des démocraties populaires, op. cit., p. 93-94 [souligné par nous].

19. ASKI, Archives du KKE, K. 382, 20/32/169. 


\section{RÉSUMÉS}

En 1968 et dans les années 1970, l'indépendance relative de la Roumanie par rapport à l'URSS permit l'accomplissement de la scission du Parti communiste de Grèce, un processus compliqué, médiatisé par les interventions multiformes de l'URSS au sein du Parti grec. La scission fut une potentialité de plus en plus apparente dès le moment où les communistes grecs prirent conscience des conséquences dramatiques de la défaite stratégique de 1949 à la fin de la guerre civile. D'un autre côté, cette période posa les jalons d'un humanisme diffus. En 1968, sous la pression du changement progressif de la politique extérieure de l'URSS et des problèmes du camp socialiste, ce courant humaniste se scinda en deux : le courant humaniste apologétique s'aligna sur la politique du PCUS; il chercha à se cramponner à la politique de Bucarest pour subsister politiquement et économiquement. Dans les deux cas, leur dépendance était absolue. L'axe moscovite et l'axe roumain n'étaient que la preuve de la défaite définitive des communistes grecs dans cette conjoncture historique précise, polarisée par la guerre froide.

In 1968 and during the 70', the relative independence of Romania from the Soviet side allowed the completion of the split of the Communist Party of Greece (KKE). This is a complicated process, mediated by the multifaceted interventions of the Soviet Union (USSR) within the Greek Party. The split was an increasingly apparent potentiality as soon as the Greek Communists realised the dramatic consequences of the strategic defeat of 1949 , following the end of the civil war. On the other hand, this period established the foundation of a vague humanism. In 1968, under the pressure of the progressive changes in the foreign policy of the USSR and the problems of the socialist camp, this mode of humanism split into two: the apologetic mode of humanism aligned itself with the policy of the Communist Party of the Soviet Union (CPSU); the centrifugal humanist mode tried to cling on to the policy of Nicolae Ceaușescu in order to survive politically and economically. In both cases, their dependency was absolute. The Russian axis and the Romanian axis are the proof of the final defeat of the Greek communists in this specific historical conjuncture, polarised by the Cold War.

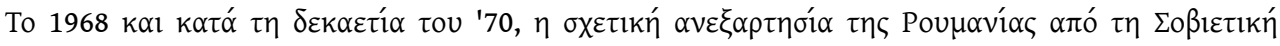

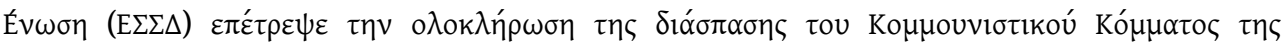

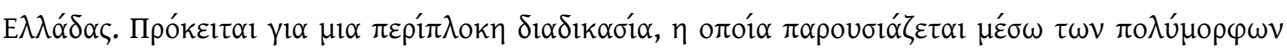

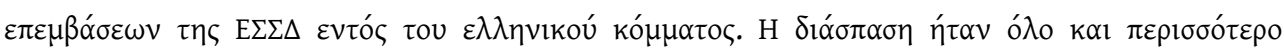

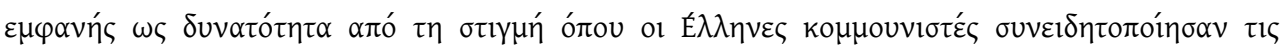

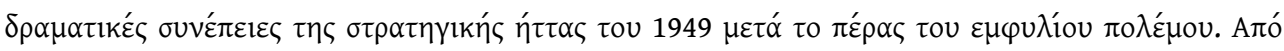

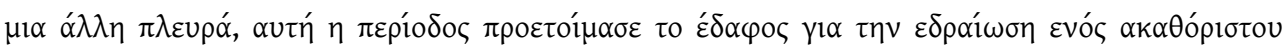

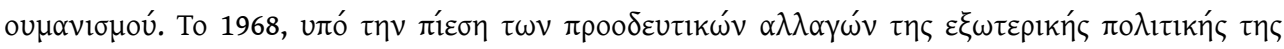

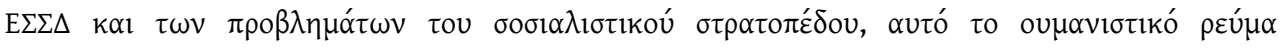

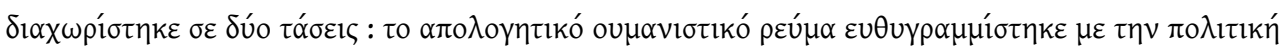

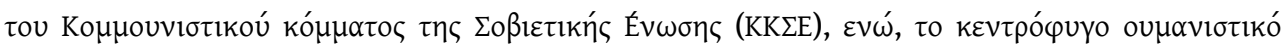

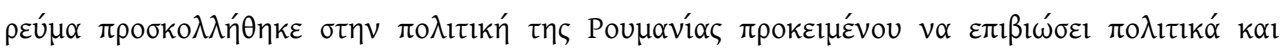

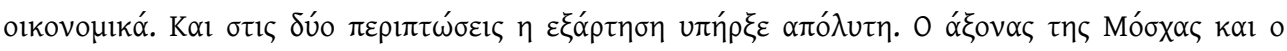

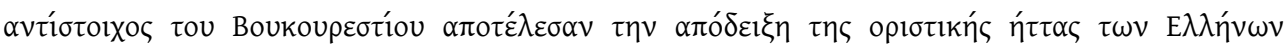

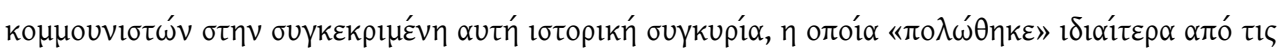

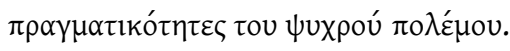




\section{INDEX}

Index géographique : Grèce, Roumanie

motsclesmk КПГ, ДЕСТАЛИНИЗАЦИЯ, РОМАНИЈА, ГРЦИЈА, ВТОРАТА ПОЛОВИНА НА ДВАЕСЕТТИОТ ВЕК, ИСТОРИЈА, ПОЛИТИЧКА ИСТОРИЈА, ЖАХАРИАДИС НИКОС (1903-1973)

Keywords : ККЕ, De-Stalinization, Greece, Rumania, Second Half of the Twentieth Century, History, Zachariadis Nikos (1903-1973), Political history

Mots-clés : KKE, KKE, déstalinisation, Zachariadis Nikos (1903-1973), Zachariadis Nikos (1903-1973), Dimitrou Panos (1917-2017), Koliyannis Kostas (1909-1979), Striggos Leonidas (1900-1983), Partsalidis Dimitrios (1903-1980)

motsclestr YKP, Destalinizasyon, Rumanya, Yunanistan, Yirminci yüzyılın ikinci yarısında, Tarih, Siyasi Tarih, Zachariadis Nikos (1903-1973)

Thèmes : Histoire, Histoire politique

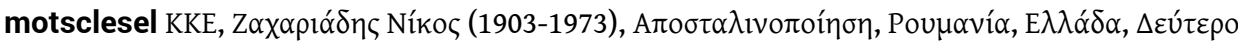

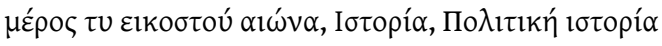

Index chronologique : vingtième siècle -- fin

\section{AUTEUR}

\section{NIKOS PAPADATOS}

Chercheur associé au Global Studies Institute (GSI) de l'université de Genève 